\title{
Body Mass Index (BMI) dependent effect of thyroid stimulating hormone (TSH) and gonadotropins on ovarian reserve markers in the secondary infertile women at fertile age.
}

Haroon Latif Khan

Lahore Institute of Fertility and Endocrinology

Komal Fatima

Biochemistry Department, Kinnaird College for Women

Shahzad Bhatti ( $\sim$ drshahzadbhatti@yahoo.com )

Lahore Institute of Fertility and Endocrinology

Sammar Nathanial

Biochemistry Department, Kinnaird College for Women

Hooria Younus

Biochemistry Department, Kinnaird College for Women

\section{Research Article}

Keywords: Secondary Infertility, Thyroid Hormones, Body Mass Index, Ovarian Reserve Markers,

Gonadotropins

Posted Date: March 4th, 2021

DOI: https://doi.org/10.21203/rs.3.rs-296169/v1

License: (c) (i) This work is licensed under a Creative Commons Attribution 4.0 International License.

Read Full License 


\section{Abstract}

Background: Infertility is a medical condition when a couple fails to conceive after having regular unprotected intercourse without the use of any contraceptive, it a complex global health issue that can be primary with no previous conception or secondary with one or more previous conceptions. A number of anomalies in the reproductive track govern the state of infertility in female of reproductive age.

Materials and Methods: The study was conducted on 100 secondary infertile women based on BMI groups \{Normal 18-23.9 kg/m² $(\mathrm{N}=35)$ and Overweight $\left.24-27 \mathrm{~kg} / \mathrm{m}^{2}(\mathrm{~N}=65)\right\}$, attending tertiary care infertility center: Lahore Institute of Fertility and Endocrinology, Hameed Latif Hospital. The present analytical cross sectional study was conducted to assess the BMI based combinatorial effect of gonadotropins with thyrotropin and ovarian reserve markers in secondary infertile women. Serum hormonal levels of TSH, LH, FSH and AMH were measured by using Roche electrochemiluminescence immunoassay (ECLIA) and AFC was recorded by transvaginal ultrasonography. The results were statistically analyzed by Spearman correlation test using XLSTAT, considered significant at $p$-value $<0.05$.

Results: A total of $18 \%$ of secondary infertile women with normal BMI were found to have a lower serum TSH levels $(<0.27 \mu \mathrm{lU} / \mathrm{ml})$ which can be characterized as hyperthyroidism as compared to overweight population. A strong significant positive correlation was found in the TSH, age and $\mathrm{BMI}$, however, these factors were found to be negatively correlated with AMH and AFC. Gonadotropins level was increased with increase in TSH levels among participants with normal BMI but decreased with TSH escalation values among overweight population.

Conclusion: TSH was found to be one of the most important diagnostic factors of infertility must be monitored in relation with other parameters (AMH, AFC, FSH, and $\mathrm{LH}$ ) in order to spot instigation point, as it directly acts upon ovulation surge by controlling gonadotropins related actions on ovarian reserve. Weight should also be assessed regularly with age to minimize the infertility issues.

\section{Background}

A number of problems associated with the female reproductive system are ensued from the anomalies mainly in the hormonal cascade of hypo-thalamic-pituitary-thyroid-adrenogonadal ovarian pivot that ultimately leads to infertility [1, 2]. Following cancer and cardiovascular diseases, infertility has become the third most prevalent disease of the world and escorts a conspicuous physiological, economical, therapeutic and psychological stresss to sufferers and the whole society that cannot be underestimated [3]. Infertility is a medical condition which can be either primary i.e, when a couple fails to conceive after two years of regular and unprotected intercourse without the use of contraception [4-6] or it can be secondary in which a couple fails to conceive for the number of children they wanted to have [7]. Multiple statutory parameters are delimited for its cause i.e., age, weight, lifestyle and family history [1]. World Health Organization has been estimated that $12-14 \%$ of couples around the globe suffered from infertility 
with $40 \%$ due to the female partner, $30 \%$ due to the male infertility and another $30 \%$ may have involved mutual problem or undiagnosed [6].

Endocrine system with its glands and hormones is second most important regulatory system of the body after the nervous system [8]. Being the most prominent factors of fertility it is a crucial demand to assess the hormonal secretions of the endocrine glands. Gonadotropins with anti-mullerian hormone and thyroid hormones from anterior pituitary and presence primordial follicles principally influence the normal reproductive health [9]. Pituitary hormones, in particular, thyroid stimulating hormone (TSH), prolactin and gonadotropins act synergistically to trigger the growth of non-growing follicles [1].

Thyroid hormones have profound effect on the menstrual irregularity and lower fecundity. Therefore, thyroid relation with infertility always considered while treating infertile women [11]. Infertility with thyroid dysfunction is categorized as decreased sex hormone binding globulin (SHBG) activity, eventually lead to increased bounded fractions of testosterone and estradiol [7].

Gonadotropins are released from the anterior lobe of the pituitary, FSH and LH are the prominent stimulators to the Gonads via bloodstream. Follicular development is induced by the FSH in the ovaries. Specifically follicle stimulating hormones (FSH) is a major promoter for orchestrating follicular development and differentiation in the granulosa cells of preovulatory follicles [8]. Luteinizing hormone (LH) plays a key role in initiation of the ovulatory process of preovulatory follicles by activating multiple cellular signaling pathways [9]. Hormonal balance between estrogen, progesterone, FSH and LH is important to induce and promote fertility. LH stimulates the release of the ovum from the ovary and surge at around day 12 of menstrual cycle leads to ovulation within 48 hours. Elevated levels of FSH and LH indicate poor follicle development and consequently, anovulatory cycles and ovarian dysfunction, respectively [1]. Reduced levels of FSH and LH may indicate hyperprolactinaemia [5].

Autopsical analysis of the human ovaries revealed that Number of growing follicles decreases rapidly with the age of the female. To assess the ovarian reserves AMH and AFC are used as the main reproductive markers. Reproductive aging is a natural phenomenon which is related to the decrease in the quality and quantity of the ovarian follicular pool. Likewise, there is an exponential decrease in the number of follicles with the increasing age, which enter the growing phase which leads them towards antral developmental stages [31]. It is certain that delivery of the monthly ovulatory follicle declines with size of the antral follicle cohort which is due to a decrease primordial reserve. Transvaginal Ultrasonography is used to visualize the antral follicular count of the ovaries.

Anti-Mullerian hormone belongs to the superfamily of transforming growth factor-beta (TGF- $\beta$ ). It is a dimeric glycoprotein which is composed of two homodimers ( $\mathrm{N}$-terminal $55 \mathrm{KDa}$ and $\mathrm{C}$-terminal 12.5 $\mathrm{KDa}$ ). $\mathrm{AMH}$ is produced by the preantral follicles in small amounts and by antral follicles in larger amounts. AMH is secreted from the granulosa layer. It has it inhibitory effects on Initial recruitment by acting on primordial follicle and on cyclic recruitment by having same effect on FSH sensitivity for follicles. From $36^{\text {th }}$ week of gestation Granulosa cells of small growing follicles produce AMH and it is 
regulated until menopause where it has undetectable concentration. The levels of $\mathrm{AMH}$ in serum reflects the follicular pool in ovaries [32]. AMH has constant level of secretions throughout menstrual cycle, unlike FSH and LH that must be measured at early follicular phase [33]. AMH has a role in folliculogenesis and also influences the follicular atresia.

Possibly, impaired thyroid function may affect the ovarian function, and prove to be a diagnostic factor in the occurrence of secondary infertility. In the present study, the relationship between thyroid function and AMH levels evaluated by comparing them in two secondary infertile groups based on normal and overweight population. This study aims to determine any association between thyroid hormones and other related hormonal factors which govern the state of infertility under the impact of BMI.

\section{Materials And Methods}

\section{Subjects}

It was a cross sectional, analytical prospective cohort study, executed at Infertility clinic of Obstetrics and Gynecology Department of Hamid Lateef Hospital. The sample population for the study was 100 cases of secondary infertile women who were visiting LIFE institute for the treatment of Infertility through IVF/ICSI from September 2017 to April 2018. The study population was divided into two group according to BMI values, and both groups were aged between 20 and 35 years. An Ethical Approval was taken from the institutional ethical committee by applying Helsinki Declarations. A signed consent was obtained from the subjects before the start of the study and to publish the study results, as required and they were assured of high confidentiality.

\section{Inclusion Criteria}

The following factors were considered while choosing the samples, women aged between 20-45 years, diagnosed with secondary infertility, one previous conception irrespective of the outcome (Birth or Miscarriage), and normal appearance of ovaries under USG. The body mass index was calculated and samples were divided into two groups: Group 1 (Normal, BMl: $18-23.9 \mathrm{~kg} / \mathrm{m}^{2}$ ) consisted of 35 and Group 2 (Overweight, BMI: $24-27 \mathrm{~kg} / \mathrm{m}^{2}$ ) comprised of 65.

\section{Exclusion Criteria}

The parameters that were adopted as exclusion criteria were ; male factor infertility and amongst female factor any patient with primary infertility, diabetes, thyroid abnormalities, polycystic ovarian syndrome, cardiovascular disorders, previous thyroid surgery, currently on thyroid medications, congenital or infectious anomalies in uterus, cervix, fallopian tube and peritoneal cavity and women using contraceptives.

\section{Ultrasonography}


Transvaginal ultrasonography of the patients was done at the $2^{\text {nd }}$ to the $5^{\text {th }}$ day of the cycle. Antral follicles size was recorded which ranges from $(2-10 \mathrm{~mm})$. The antral follicles were counted and measured in between size range from $2-8 \mathrm{~mm}$.

\section{Biochemical Analysis}

About $5 \mathrm{ml}$ of venous blood samples were collected aseptically, with the help of phlebotomist in properly labelled silica gel (clot activator) red vials from the participants after 12 hour fasting from cubital veins and allowed to coagulate for 2 hours at room temperature. The samples were obtained during the subject's early follicular phase i.e. $2^{\text {nd }}$ to $5^{\text {th }}$ day as told by the participants. Serum was isolated by centrifugation at $3000 \mathrm{rpm}$ for 10 minutes and could be stored for 5 days at $-20^{\circ} \mathrm{C}$ if not assessed immediately. Sera was analyzed for following parameters: (FSH, LH, AMH and TSH). Anthropometric measurements (BMI was calculated as per the World Health Organization recommendation) were obtained from the subjects. The biochemical measurements of hormones were done by Electrochemiluminescence Assay (ECLIA) with final chemiluminescence detection under Elecsys Roche immunoassay analyzer. The procedure was done according to the instructions provided by the manufacturer. All the tests were based on the same principle and procedure but only differ in their sample antigens. Normal range values for hormones in follicular phase were taken as: TSH $(0.27-4.2 \mu \mathrm{lU} / \mathrm{mL})$, $\mathrm{FSH}(3.5-12.5 \mathrm{mlU} / \mathrm{mL}), \mathrm{LH}(0.100-200 \mathrm{mlU} / \mathrm{mL})$ and $\mathrm{AMH}(0.01-23 \mathrm{ng} / \mathrm{mL})$.

\section{Statistical Analysis}

The patient data was categorized into two different groups and sample characteristics were expressed as mean \pm standard deviation, number percentage [n\%] median with confidence interval of $95 \%$. Using ANOVA One-way analysis difference between variance of both groups was determined and presented through interval plots. Across the two groups outcome differences were found out through two-tailed test (Kruskal-Wallis test) and categorical variables were analyzed by using $\chi 2$-test. The relationship between the variables (AMH, TSH, FSH and LH) was calculated by the Spearman's Correlation and ANOVA was used for one way analysis of variance. The prevalence of low ovarian reserve was compared between normal and overweight cohorts by logistic regression analysis. To characterize the BMI dependent changes in the study population hormonal assessments scatter plots were drawn. Statistical analysis was done using XLSTAT and SPSS (version 25; SPSS Inch., Chicago, IL, USA) software. A statistically significant $p$-value was considered as $p<0.05$.

\section{Results}

The following study was conducted to correlate the role of thyroid stimulating hormone (TSH) with ovarian reserve markers (Anti mullerian hormone; AMH and Antral Follicle Count; AFC) and gonadotropins (Follicle Stimulating Hormone; FSH and Luteinizing Hormone; LH) as a diagnostic parameter for secondary infertility in females. 
Comparison between Anthropometric measurements and other variables between group 1 (Normal) and group 2 (Overweight)

The data showed a gradual surge in the Body Mass Index (BMI) range, TSH and FSH values with increasing age, while AMH, LH and AFC levels were found to be independently distributed among two study groups (Table 1). The mean values of BMI $(25.142 \pm 0.593)$ and age $(28.985 \pm 0.868)$ in the group 2 (overweight) were clearly higher than mean values in group 1 (normal), this confirmed the selection criteria and the difference was also found to be statistically significant, p-value $<0.0001$ (Table 1). In Figure 1, the intervals had different centers but slightly different spread with $95 \%$ confidence interval for mean values. The mean value of TSH in group $1(0.423 \pm 0.233)$ was found to be lower than group 2 $(1.087 \pm 0.233)$ mean values as shown in Table 1. Luteinizing hormone, anti mullerian hormone and antral follicle count for both groups showed slight difference their mean values and the differences was also found to be statistically insignificant as $p$-value $>0.1$. The intervals had different centers in plot $a \& b$ (Figure 1) but slightly different spread with $95 \%$ confidence interval for mean and population means were statistically significant because intervals for mean didn't overlap. The population spread was also different for AMH and AFC but due to overlapping in between means it was considered insignificant ( $p$ value $>0.05$ ).

\section{Correlation of different parameters of patients with TSH in both study groups.}

The BMI and age of the two groups were correlated with themselves and other parameters included in the study. Age and TSH were found to have a highly significant positive correlation with each other with increasing BMI in both groups (r-value 0.949; 0.936, p-value; <0.0001). There was a moderate positive correlation observed between FSH and LH with TSH in normal group and a low negative correlation in overweight group, as correlation coefficients for both groups differ. The relation was highly significant for normal group because $p$-values were less than 0.05 but insignificant for overweight as $p$-value $>0.05$ (Figure $2 \&$ Table 2). A moderate negative correlation observed between TSH and ovarian reserve markers (AMH and AFC) in both study groups, as correlation coefficients were less than 0 . The relation was insignificant because $p$-values were greater than 0.05 for both cases (Table $2 \&$ Figure 2 ).

\section{Evaluation of endocrine hormonal parameters and ultrasound findings}

A significantly higher concentration of serum FSH levels was perceived (95\% Cl; $2.04 ; 20.14) \mathrm{LH}(95 \% \mathrm{Cl}$ : $3.2 ; 10.6)$ and a raised $\mathrm{LH} / \mathrm{FSH}$ ratio $(95 \% \mathrm{Cl} ; 1.6 ; 0.5)$ than overweight group 2 as showed in the Table 3. $\mathrm{AMH}$ and AFC data was found to be directly distributed among the both study cohorts uniformly as $~ 75 \%$ of cases have AMH in between 4.5-7.9 ng/ $\mathrm{ml}$ range and AFC in between 21-45 at confidence interval of 95\% (Table 3).

\section{Thyroid function status in study population}

Out of the 100 secondary infertile women enrolled in the study, 18 were hyperthyroid, as their TSH levels were found to be lower than $0.027 \mu \mathrm{lU} / \mathrm{ml}$. Most the patients $(82 \%)$ in the study population were euthyroid 
which highlighted the selection criteria for cases with no previous thyroid history. It was also noted that hyperthyroid were from normal BMI with lower age range (24-27) with no case in overweight with higher age (28-30) (Table 4).

\section{Discussion}

Infertility is an emerging issue of the present era with $14 \%$ prevalence around the world. The present study was conducted on 100 secondary infertile women who attended LIFE institute of infertility for a number of parameters which were correlated and compared in two different BMI groups; normal and overweight. Anti-mullerian hormone, thyroid stimulating hormone, luteinizing hormone, follicle stimulating hormone and antral follicle count were analyzed for the two groups. The anti-mullerian hormone and antral follicle count were recorded as the markers for the ovarian reserve. All the variables were assessed through XLSTAT software by their means and standard deviations along with quartiles and median values. A number of previously reported studies had explained the prevalence of infertility in the present era worldwide [2-6, 20-21]. Fupare et al. worked on the effect of hypothyroidism with hyperprolactinemia on the occurrence of infertility with fluctuations in the levels of FSH and LH among secondary infertile women [1]. Hypothyroidism, with elevated serum TSH levels and diminished ovarian reserve markers was also reported by Krassas et al in their study and suggested that these hormone were negatively correlated with each other [12]. Sammour et al. reported a significant negative correlation between thyroid stimulating hormone and anti mullerian hormone in infertile patients with other hormonal parameters including FT3, FT4 and gonadotropins [22]. A highly positive correlation was found between age and BMI as indicated by the $r$-value ( $r=0.949$ in normal and $r=0.887$ in overweight secondary infertile women) and $\mathrm{p}$-value $<0.05$. This suggested that as age increases the BMI also increase as previously observed in the study of Krassas et al. However, these results were found to be inconsistent with the study by Manavi et al. In a study conducted by Poppe et al. variations in the TSH levels were reported among varying BMI groups. This result was in line with the present study which indicated a highly positive relationship ( $p$ value $<0.0001$ ) between TSH, age and BMI highlighting an increasing trend in the TSH levels with rise in age and BMI. This association also links the fact that higher TSH leads to hypothyroidism as previously reported by Joshi et al in his study on infertile women and associated hypothyroidism with menstrual irregularities in $28 \%$ of 171 infertile population while just $4 \%$ among control population [23]. According to the present study anti mullerian hormone and antral follicle count were found to be negatively correlated with thyroid stimulating hormone and luteinizing hormone with consistently increase in age and BMI. Although antral follicle count had a weak positive correlation in group 1 but had a negative correlation in group 2, as it might be the case that this was due to the variation in the sample data where group 1 had almost same minimum and maximum values indicating that antral follicle count remains same with the variation in BMI ranges. This suggested that ovarian reserve would be decreased with increase in body mass index with the age. Battikhi et al. had presented the same correlation results of ovarian reserve markers and TSH with the present study, as these factors were found to be negatively correlated in the infertile patients of different age groups [24]. In the present study follicle stimulating hormone perceived to had an insignificant positive correlation with ovarian reserve markers, age and BMI in group 1 
population ( $p$-value $>0.05$ ) but negatively correlated with group 2 ( $p$-value $>0.05)$. The findings of this study elaborated that FSH has higher concentration at younger age with normal BMI than at an older age with increase in BMI in secondary infertile women. In agreement with the study of Sammouro et al. AMH with AFC was responsible for assessing the ovarian reserve along with the FSH in infertile women with negative correlation and gonadotropins were also reported as markers for the ovarian reserve of infertile individuals [25]. An increased prevalence of thyroid autoimmune disease and nodular thyroid disease as well as changes in the pituitary-thyroid axis are found to be associated with aging [17]. TSH is secreted from the pituitary gland and it stimulates the prolactin secretion which in turn lowers the release of gonadotropin releasing hormone from the hypothalamus that results in the lower gonadotropin secretions. In the current study gonadotropins were found to be positively correlated ( $p$-value $<0.05)$ with each other and TSH at a younger age with normal BMI but the results were opposed with an increasing age and BMI ( $p$-value>0.05). This finding showed that thyrotropin and gonadotropins levels were negatively regulated by age and BMI because in young patients with normal body mass index these hormones had elevated levels than in the older overweight patients. Fupare et al. in their study found that FSH and LH levels were lower than TSH in infertile women as compared to controls [1]. Acharya et al. observed the levels of FSH and LH in different BMI groups as regard with age and they found the same results as in this study [26]. In accordance with the study by Krassas at al. hyperthyroidism was also found to have effects on the gonadotropin levels of the normal secondary infertile women of older age [12]. The changes in pituitary-thyroid-ovarian axis were found to be associated with aging as well as increase or decrease in the BMI values according to previous studies. It had also been studied that when there is an absence of thyroid disease, aging had effect on the reduced secretions of TSH hormone [18]. However, it was shown in the data from NATIONAL Health and Nutrition Examinations Survey III (NHANES III) that TSH serum levels increase with age in people with no history of thyroid disease when there in iron sufficiency [19].

\section{Conclusion}

This study of secondary infertile women at the LIFE institute of infertility found that BMI, age and TSH were positively correlated with each other having a significant negative correlation with $\mathrm{AMH}$ and antral follicle count in two BMI groups. FSH and LH were also found to be positively correlated with each other and TSH in group 1 (normal), however, they were negatively correlated with TSH and each other in group 2 (overweight). This showed that TSH, FSH and LH levels were affected by increase in the BMI. AMH can be used as a good ovarian reserve marker for the secondary infertile women than other hormonal analysis. These findings suggested that, even within what generally is considered normal TSH range, close attention should be paid in infertile women to TSH values along with other hormonal assessments and BMI.

\section{References}


1. Fupare S, Gadhiya BM, Jambhulkar RK, Tale A. Correlation of Thyroid Hormones with FSH, LH and Prolactin in Infertility in the Reproductive Age Group Women. Age. 2015;23(2.48):27-575.

2. Goswami B, Patel S, Chatterjee M, Koner BC, Saxena A. Correlation of prolactin and thyroid hormone concentration with menstrual patterns in infertile women. Journal of reproduction \& infertility. 2009 Oct;10(3):207.

3. Cong J, Li P, Zheng L, Tan J. Prevalence and risk factors of infertility at a rural site of northern China. PloS one. 2016 May 13;11(5):e0155563.

4. Yadav A, Arora M, Saini V, Bhattacharjee J, Jain A. Serum gonadotropin and prolactin levels in females with primary infertility and thyroid dysfunction in North Indian population. Journal of Infertility and Reproductive Biology. 2014;2(3):88-91.

5. Sami N, Ali TS, Wasim S, Saleem S. Risk factors for secondary infertility among women in Karachi, Pakistan. PloS one. 2012 Apr 27;7(4):e35828.

6. Bassey IE, Udoh AE, Essien OE, Isong IK, Gali RM, Archibong EE. Thyroid hormones and prolactin levels in infertile women in southern Nigeria. Journal of clinical and diagnostic research: JCDR. 2015 Mar;9(3):0C13.

7. Weiss RV, Clapauch R. Female infertility of endocrine origin. Arquivos Brasileiros de Endocrinologia \& Metabologia. 2014 Mar;58(2):144-52.

8. Habbu PP, Shaikh AK. Study of Thyroid Dysfunction in Association with Infertility.

9. Cramer DW, Sluss PM, Powers RD, McShane P, Ginsburgs ES, Hornstein MD, et al. Serum prolactin and TSH in an in vitro fertilization population: is there a link between fertilization and thyroid function? J Assist Reprod Genet. 2003;20(6):210-5.

10. Armada-Dias L., Carvalho J.J., Breitenbach M.M., Franci C.R., Moura E.G. Is the infertility in hypothyroidism mainly due to ovarian or pituitary functional changes? Braz J Med Biol Res. 2001;34 (9):1209-15.

11. Association of thyroid dysfunction among infertile women visiting infertility center of Om Hospital, Kathmandu, Nepal B Rijal,1 R Shrestha2 and B Jha1.

12. Krassas GE, Poppe K, Glinoer D. Thyroid function and human reproductive health. Endocr Rev. 2010;31(5):702-755.

13. Redmond GP 2004 Thyroid dysfunction and women's reproductive health. Thyroid 14(Suppl 1):S5S15

14. Hyperprlactinemia Abha Majumdar, Nisha Sharma Mangal

15. Mishra R, Baveja R, Gupta V. Prolactin level in infertility with menstrual irregularities. J Obstet Gynecol India. 2002;52:4.

16. Assessment of Serum Luteinizing Hormone, Follicle Stimulating Hormone and Esteradiol Levels among Sudanese Infertile Females Dr .Omer Mohamed Shoaib.

17. Ahmed KA, Elmahadi SA, Hamza AM, Ali AE. Assessment of thyroid functions test among hyperprolactinemic Sudanese infertile females. Health Science Journal. 2016;10(6):1. 
18. Hollowell JG, Staehling NW, Flanders WD, Hannon WH, Gunter EW, Spencer CA, Braverman LE. Serum TSH, T4, and thyroid antibodies in the United States population (1988 to 1994): National Health and Nutrition Examination Survey (NHANES III). The Journal of Clinical Endocrinology \& Metabolism. 2002 Feb 1;87(2):489-99.

19. Bellver J. Body weight and fertility. Reproductive Biology Insights. 2009 Sep 2;2009(2):25-30.

20. Adamson P, Krupp K, Freeman A, Klausner J, Reingold A, Madhivanan P. Prevalence \& Correlates of Primary Infertility among Young Women in Mysore, India. The Indian Journal of Medical Research. $2011 ; 134: 440$.

21. Kumar P, Sait SF. Luteinizing hormone and its dilemma in ovulation induction. Journal of human reproductive sciences. 2011 Jan;4(1):2.

22. Strachan M and Newell-Price J. Endocrine disease. In: Walker BR, College NR, Ralston SH and Penman ID. Davidson's Principles and Practice of Medicine. 22nd edition. China: Churchill Livingstone, Elsevier; 2014. p 743-744.

23. Poppe K, Velkeniers B. Female infertility and the thyroid. Best Practice \& Research Clinical Endocrinology \& Metabolism. 2004 Jun 1;18(2):153-65.

24. Battikhi M, Zqlam W, Banat E and Battikhi Q. Correlation of Antimullerian Hormone (AMH) and Follicle Stimulating Hormone (FSH). ECronicon Microbiology 4.1 (2016): 617-622.

25. Sammouro K, Ho C, Shyong W, Huang C, Tsai S, Cheng H, Chou L, Lin C, Li H. Anti-Mullerian hormone serum level as a predictive marker of ovarian function in Taiwanese women. Journal of the Chinese Medical Association. 2012; 75:70-4.

26. Acharya N, Acharya S, Shukla S, Inamdar SA, Khatri M, Mahajan SN. Gonadotropin levels in hypothyroid women of reproductive age group. The Journal of Obstetrics and Gynecology of India. 2011 Oct 1;61(5):550-3.

27. Pellatt L, Hanna L, Brincat M, Galea R, Brain H, Whitehead S, Mason H. Granulosa cell production of anti-Mullerian hormone is increased in polycystic ovaries. The Journal of Clinical Endocrinology \& Metabolism. 2007; 92:240-5.

28. La Marca A, Sighinolfi G, Radi D, Argento C, Baraldi E, Artenisio A, Stabile G, Volpe A. Anti-Müllerian hormone $(\mathrm{AMH})$ as a predictive marker in assisted reproductive technology (ART). Human reproduction update. 2009; 16:113-30.

29. Al-Azzawi OD, Al-Hadithy AH, Amen SS. The effect of thyroid dysfunction on anti-mollurian hormone concentration in the infertile women at the fertile age. International Journal of Science and Nature. 2015;6(1):45-50.

30. Scheffer G, Broekmans F, Dorland M, Habbema J, Looman C, te Velde E. Antral follicle counts by transvaginal ultrasonography are related to age in women with proven natural fertility. Fertility and sterility. 1999; 72:845-51.

31. Pellatt L, Hanna L, Brincat M, Galea R, Brain H, Whitehead S, Mason H. Granulosa cell production of anti-Mullerian hormone is increased in polycystic ovaries. The Journal of Clinical Endocrinology \& Metabolism. 2007; 92:240-5. 
32. Kim B. Thyroid hormone as a determinant of energy expenditure and the basal metabolic rate. Thyroid. 2008; 18:141-4.

\section{Tables}

Table 1: Comparison among different parameters between group 1 (Normal) and group 2 (Overweight).

\begin{tabular}{|llll|}
\hline Variables & $\begin{array}{l}\text { Normal } \\
(\mathbf{n}=35) \\
\text { Mean } \pm \text { SD }\end{array}$ & $\begin{array}{l}\text { Overweight } \\
(\mathbf{n}=65)\end{array}$ & p-value \\
Age (years) \pm SD & \\
\hline BMl $\left(\mathrm{kgm}^{-2}\right)$ & $25.857 \pm 0.899$ & $28.985 \pm 0.868$ & $<0.0001^{*}$ \\
\hline Endocrinal Assessments & & & \\
\hline TSH & $0.423 \pm 0.233$ & $1.087 \pm 0.233$ & $<0.0001^{\star}$ \\
\hline FSH & $6.295 \pm 2.037$ & $7.858 \pm 3.921$ & $0.032^{\star}$ \\
\hline LH & $6.147 \pm 2.474$ & $6.913 \pm 2.241$ & 0.123 \\
AMH & $5.193 \pm 1.390$ & $5.482 \pm 1.816$ & 0.419 \\
\hline AFC & $29.971 \pm 10.171$ & $28.231 \pm 11.642$ & 0.463 \\
\hline
\end{tabular}

Data were presented as mean \pm SD. For both normal and overweight groups, and a statistical difference was tested across different age groups. Data for the total infertile patients are also subjected to statistical differences, and $p>0.05$ considered statistically significant using One-way ANOVA. ${ }^{*}$ ) statistically significant.

Table 2: Correlation of different parameters of patients with TSH in both study groups. 


\begin{tabular}{|c|c|c|c|}
\hline \multicolumn{2}{|c|}{ Parameters } & \multirow{2}{*}{$\begin{array}{l}\text { Group } 1 \\
(n=35) \\
<0.0001^{*}\end{array}$} & \multirow{2}{*}{$\begin{array}{l}\text { Group } 2 \\
(n=65) \\
<0.0001^{\star}\end{array}$} \\
\hline Age & $\mathrm{p}$-value & & \\
\hline & r-value & $0.949 * \star$ & $0.936 * \star$ \\
\hline \multirow[t]{2}{*}{ BMI } & $\mathrm{p}$-value & $<0.0001^{*}$ & $<0.0001^{\star}$ \\
\hline & r-value & $0.973^{\star \star}$ & $0.971^{\star \star}$ \\
\hline \multirow[t]{2}{*}{ FSH } & $p$-value & $0.015^{\star}$ & 0.634 \\
\hline & r-value & 0.409 & -0.060 \\
\hline \multirow[t]{2}{*}{ LH } & $\mathrm{p}$-value & $0.031 *$ & 0.193 \\
\hline & r-value & 0.367 & -0.163 \\
\hline \multirow[t]{2}{*}{ AMH } & $\mathrm{p}$-value & 0.719 & 0.258 \\
\hline & r-value & -0.063 & -0.142 \\
\hline \multirow[t]{2}{*}{ AFC } & $p$-value & $0.544^{\star \star}$ & 0.058 \\
\hline & r-value & 0.106 & -0.237 \\
\hline
\end{tabular}

(*) Statistically significant differences and $(* *)$ highly positive spearman correlation coefficients.

Table 3: Endocrine and Ultrasonographic features of the study groups evaluated on 2 nd to 5 th day of menstrual cycle. 


\begin{tabular}{|c|c|c|c|}
\hline Parameters & $\begin{array}{l}\text { Group } 1 \\
\text { (Normal) }\end{array}$ & $\begin{array}{l}\text { Group } 2 \\
\text { (Overweight) }\end{array}$ & Total \\
\hline Number of women [n\%] & 35 & 65 & 100 \\
\hline \multicolumn{4}{|l|}{ Endocrine parameters } \\
\hline \multicolumn{3}{|l|}{ [median ( $95 \%$ population limit)] } & \\
\hline \multicolumn{4}{|l|}{ AMH (ng/ml) categories [n (\%)] } \\
\hline$\cdot \quad<0.7$ & $0(0)$ & $0(0)$ & 0 \\
\hline . $\quad 0.7-4.5$ & $8(8)$ & $16(16)$ & 24 \\
\hline . $\quad 4.5-7.9$ & $27(27)$ & $48(48)$ & 75 \\
\hline$\quad \geq 8.0$ & $0(0)$ & $1(1)$ & 1 \\
\hline FSH (IU/L) [median (95\% population limit)] & $6.35(2.89 ; 11.32)$ & $7.45(2.04 ; 20.14)$ & \\
\hline \multicolumn{4}{|l|}{ FSH (IU/L) categories [n (\%)] } \\
\hline . $\quad<4$ & $7(7)$ & $13(13)$ & 20 \\
\hline . 5-8 & $24(24)$ & $38(38)$ & 62 \\
\hline . $\quad 9-14$ & $4(4)$ & $8(8)$ & 12 \\
\hline . $\quad 15-20$ & $0(0)$ & $6(6)$ & 6 \\
\hline LH (IU/L) [median (95\% population limit)] & $5.37(3.01 ; 10.6)$ & $6.63(3.2 ; 10.6)$ & \\
\hline $\begin{array}{l}\text { LH/FSH-ratio (IU/L) } \\
\text { [median ( } 95 \% \text { population limit)] }\end{array}$ & $0.8(1 ; 0.9)$ & $0.9(1.6 ; 0.5)$ & \\
\hline \multicolumn{4}{|l|}{ Ultrasonography parameters } \\
\hline $\begin{array}{l}\text { Total number of AFC } \\
\text { [median ( } 95 \% \text { population limit)] }\end{array}$ & $30(3 ; 48)$ & $30(5 ; 48)$ & \\
\hline \multicolumn{4}{|l|}{ AFC categories [n (\%)] } \\
\hline . $\quad<80$ & $1(1)$ & $2(2)$ & 3 \\
\hline . $9-20$ & $4(4)$ & $11(11)$ & 15 \\
\hline . $\quad 21-45$ & $27(27)$ & $49(49)$ & 76 \\
\hline . $\quad>46$ & $3(3)$ & $3(3)$ & 6 \\
\hline
\end{tabular}


Data are presented as number [\%age] and median [95\% population limits]. For both normal and overweight, and a statistical difference was tested across different age variables.

Table 4: Thyroid Profile in group 1 (Normal) and group 2 (Overweight).

\begin{tabular}{|llll|}
\hline & Group 1 & Group 2 & Total \\
\hline Hypothyroid & 18 & 0 & $18 \%$ \\
\hline Euthyroid & 17 & 65 & $82 \%$ \\
\hline Hyperthyroid & 0 & 0 & $0 \%$ \\
\hline
\end{tabular}

Data presented here as number percentage values with $95 \%$ population limits and had been distributed between normal and overweight. Hyperthyroid patients were related to group 1 which constituted of cases with normal BMI and 24-27 years of fertile age.

\section{Figures}

a

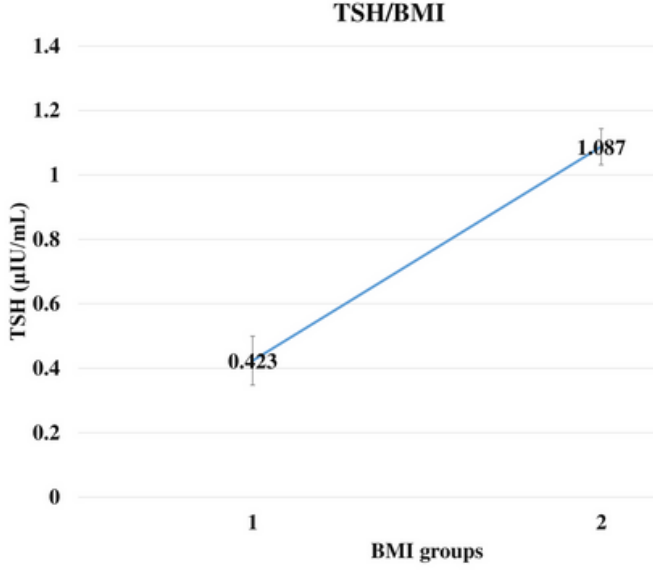

AMH/BMI

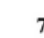

6

突 4

2

1

0

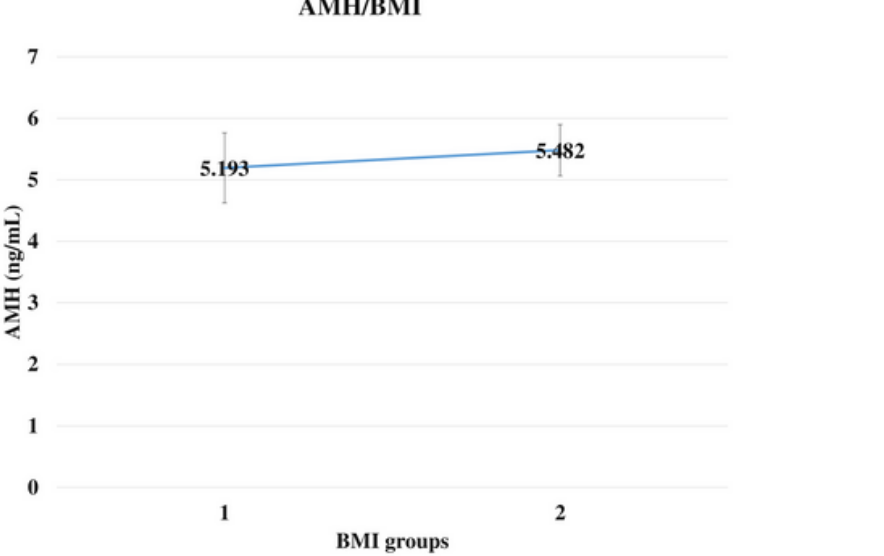

b

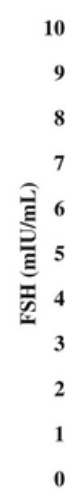

d

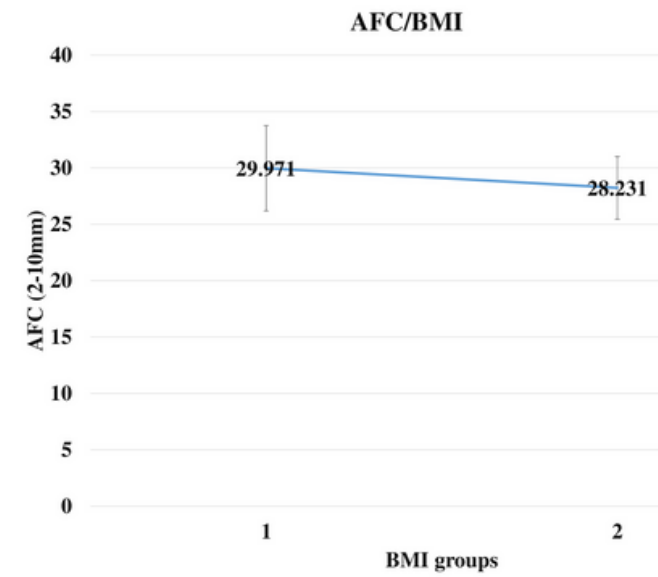


Figure 1

The interval plots were used to observe the comparison results of all the variables between two BMI groups. a) Comparison of TSH mean values among BMI groups. b) Comparison between FSH mean values in group 1 and group 2. c \& d) Comparison of mean values of AMH and AFC in both study groups. The intervals differently spread with $95 \%$ confidence interval for mean + standard deviation.

a

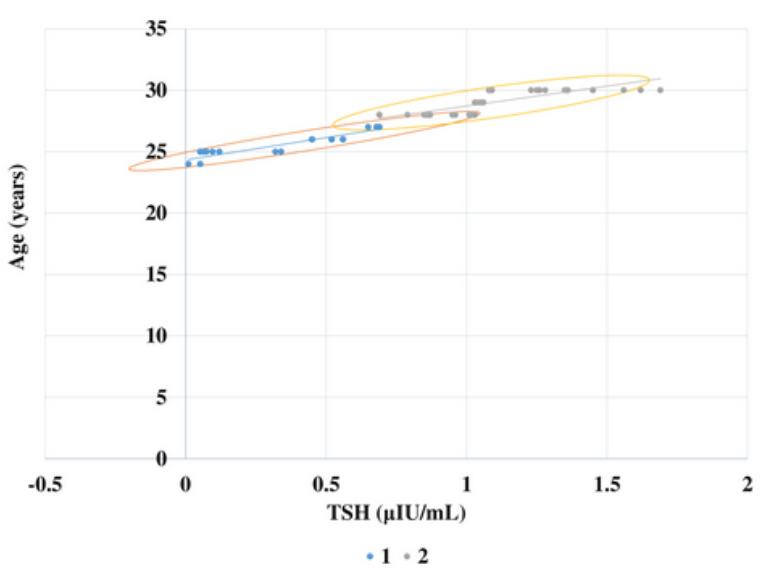

c

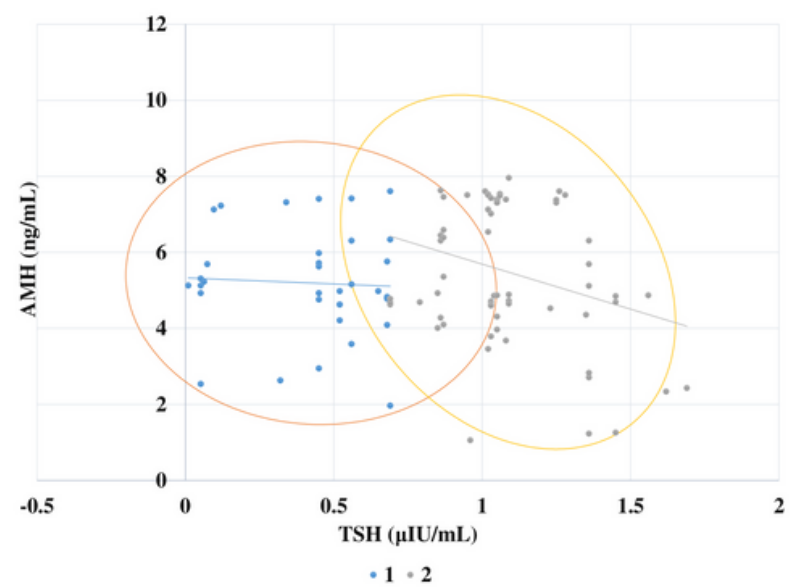

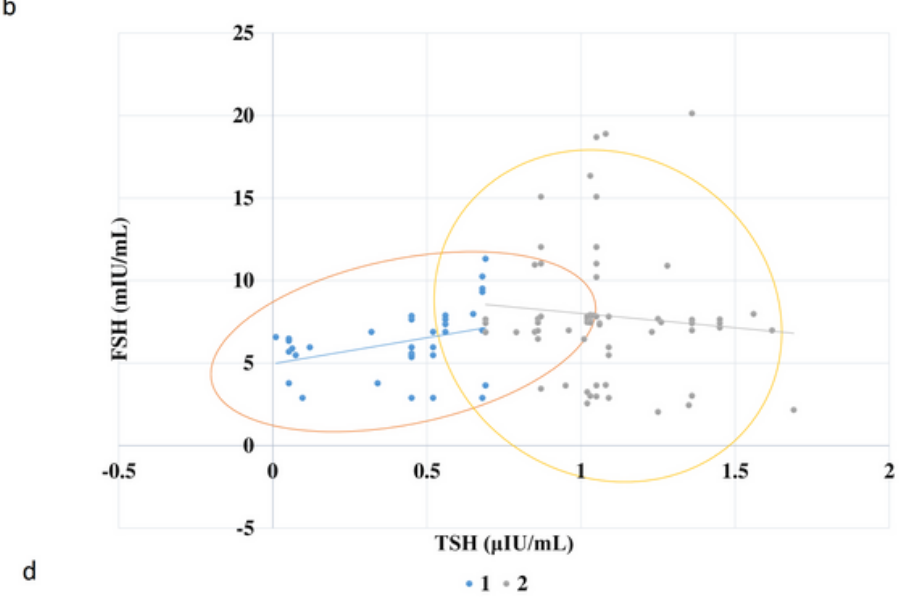

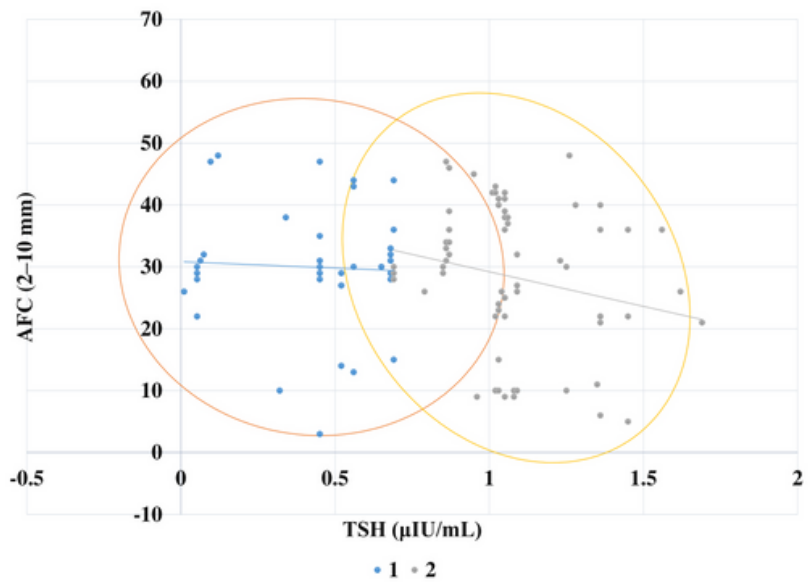

\section{Figure 2}

Scattered plots represent the linear association between age, Follicle stimulating hormone and ovarian reserve markers in secondary infertile patients with normal verses overweight. a) Correlation plot of TSH against age in group 1 and group 2 (p-value<0.0001), b) Correlation plot of TSH and FSH in group 1 and group 2. c \& d) The BMI-dependent decline in the ovarian reserve markers with increasing TSH levels. 